\title{
СОЦИАЛЬНАЯ ЗНАЧИМОСТЬ ИЗУЧЕНИЯ РЕЛИГИИ В ВИЗУАЛЬНОЙ ФИЛОСОФИИ
}

\section{SOCIAL IMPORTANCE OF STUDYING RELIGION IN VISUAL PHILOSOPHY}

\section{A. Lavrentieva}

Summary: The article examines the role of visualization in the spiritual and moral development of an individual. Visual philosophy explores the prospects for the formation of visual thinking. Difficulties of perception and decoding of information are associated with an excessive actualization of the role of visualization in modern education. Among the methods of visual structuring, it is necessary to single out structural and logical schemes. The possibilities and risks of studying religion by digital philosophy are presented.

Keywords: visualization, visiosophy, religion, spiritual and moral development, Digital Philosophy, Digital Humanities.
$P$ елигия как социальный институт выполняет основную группу функций, обеспечивающих относительно стабильное существование общества. В данной практике особое внимание уделяется воспитательной, образовательной деятельности института. Социум формирует социальные связи внутри собственной социальной структуры, создавая границы, которые регулируют социальные институты, в том числе религиозный, что позволяет выстроить стройную систему взаимодействий. Эти пределы выражаются в правилах, нормах, традициях, законах, принципах, категориях, которые передаются из поколения в поколение посредством словесных формулировок, фиксированных текстов, графических схем, таблиц, культурных символов, иконографии и т.д., в том числе в образовательном пространстве.

Как продукт человеческой деятельности, религия применяет особые способы представления религиозной информации, то есть визуализацию. Более того, не все компоненты в религии могут быть объяснены непосредственно только терминами, категориями. В данном случае религии помогают визуальные наглядные образы, к примеру, символы рыбы в христианстве, меча в сикхизме, лотоса в буддизме, многоликости в индуизме, полумесяца в исламе, которые непосредственно доносят определенное знание до субъекта, объединяют в общину, компенсирует социальную аномию. Религия, как социальный институт, обеспечивает нормализацию социальных процессов и стабилизацию общества.

Духовно-нравственное воспитание является одной

\author{
Лаврентьева Анна Юрьевна \\ к.ф.н., старший преподаватель, Северный \\ государственный медицинский университет \\ (2. Архангельск) \\ Lavrenty0719@mail.ru
}

Аннотация: В статье рассматривается роль визуализации в духовно-нравственном развитии личности. Визуальная философия исследует перспективы формирования визуального мышления. Трудности восприятия, раскодирования информации сопряжены с чрезмерной актуализацией роли визуализации в современном образовании. Среди методов визуального структурирования необходимо выделить структурно-логические схемы. Представлены возможности и риски изучения религии цифровой философией.

Ключевые слова: визуализация, визиософия, религия, духовно-нравственное развитие, Digital Philosophy, Digital Humanities.

из основных задач религии как социального института. Каждая религиозная система предлагает принципы духовного самосохранения, примеры добродетельного поведения. Так, нравственный подвиг в христианстве (католицизме, православии и протестантизме) выражается в категориях: возрождение, обращение, оправдание, освящение, прославление. «Тоска по новому человеку»[1] есть главный принцип строительства христианского образа жизни, где Абсолют выступает воплощением добродетели, к которой должен устремить свой взор человек. Протестантизм определяет веру как единственное важное дело совершенствования, что следует наполнить обязательным чтением Библии. Католическое вероучение уделяет внимание почитанию Христа и Богоматери Марии. Достижение гармонии человеком есть совокупность разных аспектов, морали и призвания особого художества (милосердия и любви). Добрые дела, борьба с грехом, труд, жизнь в вере, любви и благодати, посредством участия в таинствах направляют к нравственному подвигу православного верующего человека.

Мировые религии (ислам, буддизм и христианство) формируют концепцию нравственного воспитания, учение нравственного закона, основанные на добродетелях. Наглядно данный процесс воспитания добродетелям можно представить в виде двух схем (рис. № 1, № 2), которые характеризуют сложную, трудоемкую систему духовного развития человека в мировых религиях.

Иисус в христианстве, Мухаммед в исламе, Будда в 


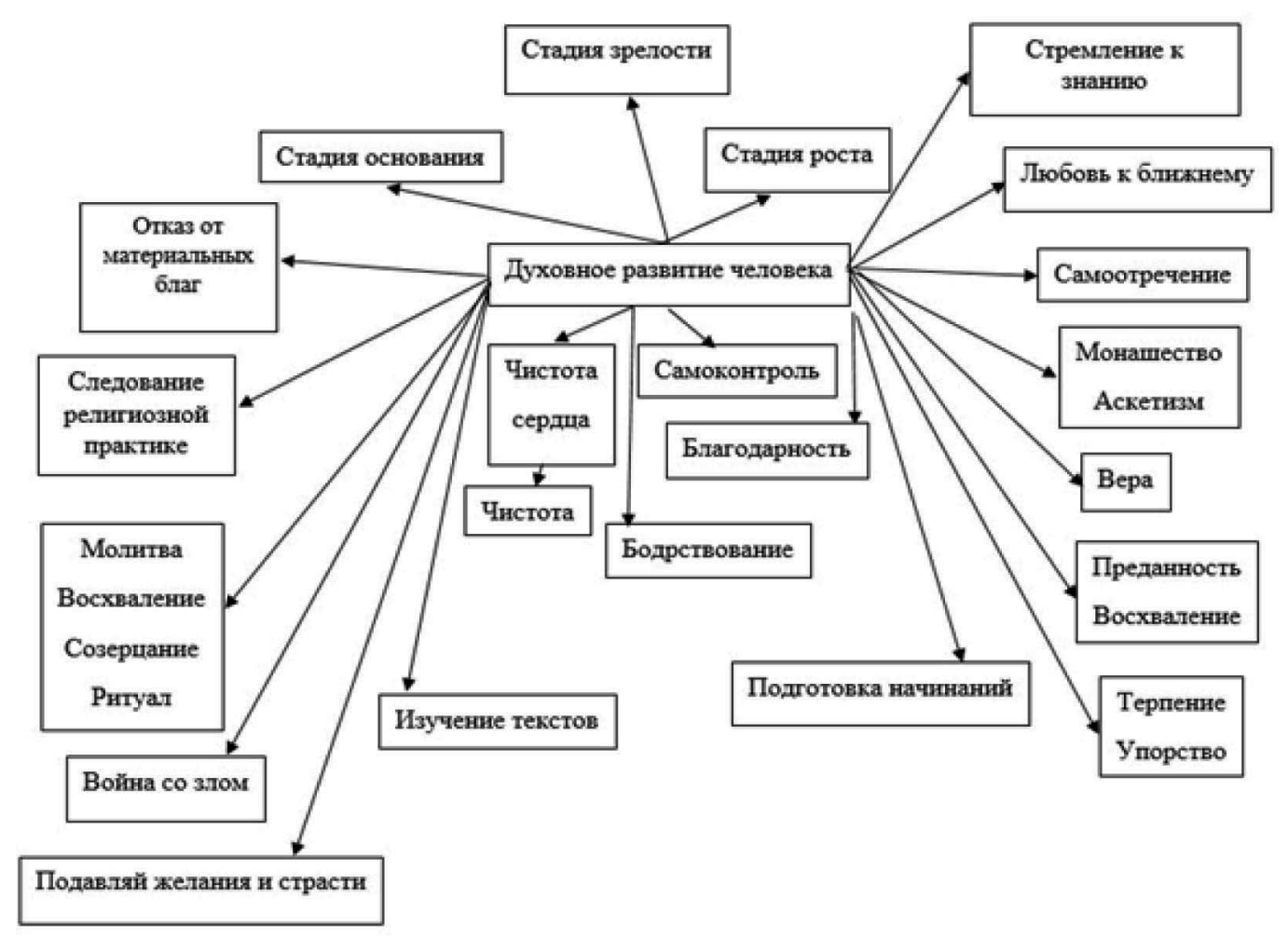

Рис. 1. Духовное развитие человека в мировых религиях. Сходство

буддизме есть эталоны совершенства. Путь духовного совершенствования включает три ступени: основание, рост и зрелость, последняя из которых является пределом духовного развития. Это стадия арханта, единения с Христом, святого, человека, приближенного к Богу, бодхисатвы.

Духовно-нравственное развитие человека различно определяют в мировых религиях. В исламе это духовное самосовершенствование, которое возможно в результате выполнения установлений Аллаха. В буддизме это самосовершенствование, то есть развитие человека собственными усилиями при прохождении всех ступеней совершенства, где цель - отрешение от внешнего мира. В христианстве это духовное совершенствование на основе веры и добрых дел.

Религия является одним из объектов философского изучения, современные способы которого актуализируют визуализацию. Доктор философских наук А.В. Макулин дает определение визуализации философии как способов представления философской информации в виде, удобном для зрительного наблюдения и анализа [5, с. 63]. Термином «цифровая визиософия» А.В. Макулин формулирует наглядное, интерактивное представление о философском знании, его визуально-семантическом кодировании и распознавании [5, с. 70]. А.А. Ромащенко и М.А. Ромащенко называют данный метод современным и популярным корпусом цифровых методов - Digital
Philosophy - и суммой наук о духе, преломленная сквозь призму цифрового мастерства - Digital Humanities, обосновывают наличие в учебном процессе трех принципов онтологии визуального образа в философии: абстрактное мышление, способность к воображению и обобщению, которые имеют преимущества перед схематичной философской визуализацией [10, с. 40, 41]. Следовательно, философское обоснование проблем визуализации образования, философии и религии, актуально.

Цель духовно-нравственного развития - сформировать когнитивную, ценностно-смысловую сферу личности. В данном процессе образовательные институты выполняют важную задачу. С позиции кандидатов педагогических наук И.В. Тихомировой, И.И. Иванова, П.Г. Омаровой, визуализация учебной информации позволяет решить определенные задачи: обеспечить интенсификацию обучения, активизировать учебную и познавательную деятельность, сформировать и развить критическое и визуальное мышление, эвристическое восприятие, передать знаний и распознать образы, повысить визуальную грамотность и визуальную культуру [11, с. 309]. Как отмечает Д.В. Рахинский, «тенденция демократизации системы ... образования отражается в развитии дистанционных форм обучения, появление которых непосредственно связано с развитием компьютерных сетей, позволяющих желающим повысить образование, получить доступ к учебно-методическому массиву информации учебного заведения». [8, с. 205]. 


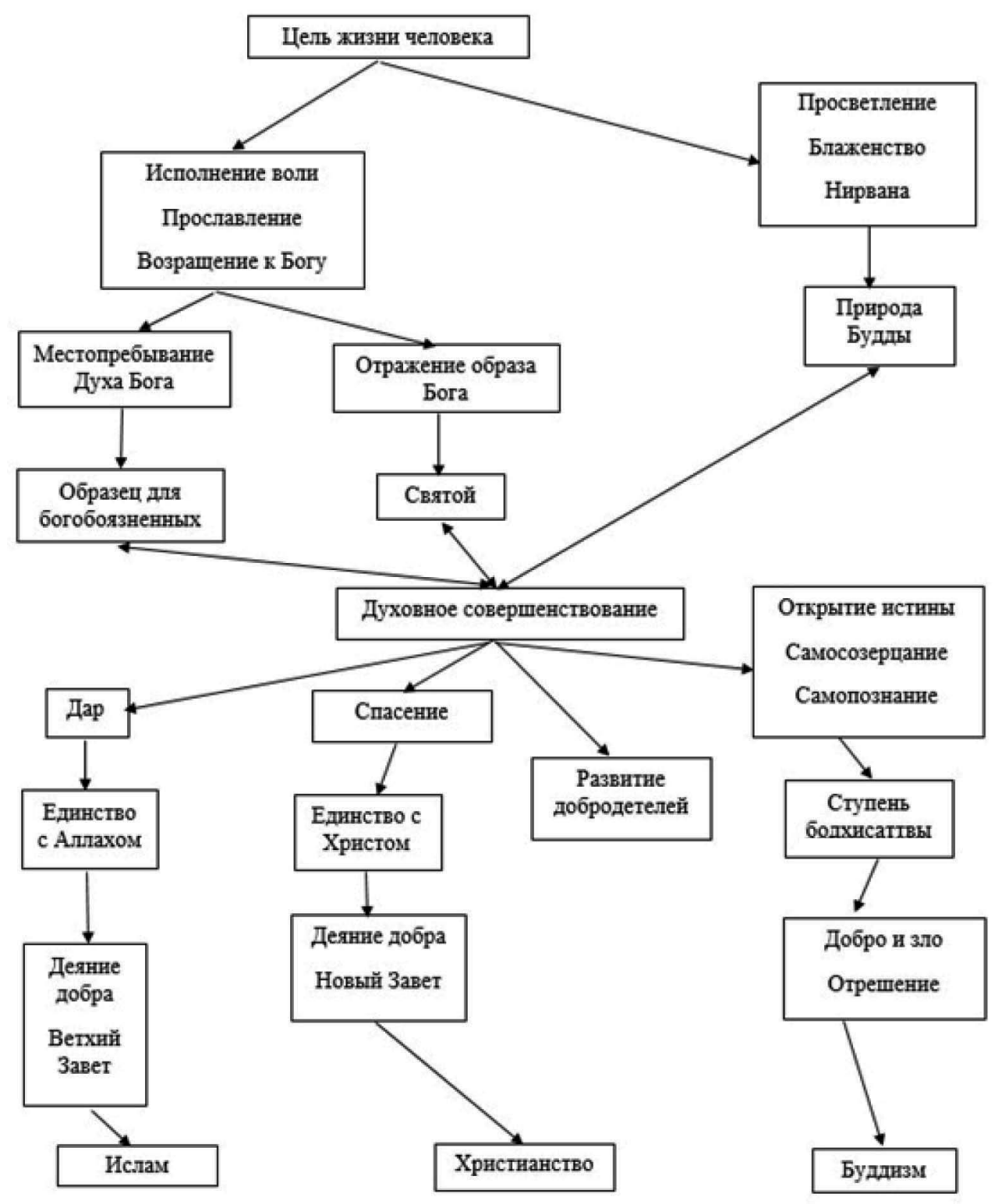

Рис. 2. Духовное развитие человека в мировых религиях. Различие

Применяя визуализацию, как способ представления информации в образовательном процессе, преподаватель более эффективно раскроет смысл и значение объясняемого явления, предмета изучения. Полякова Е.В. считает, что на практике применять необходимо именно структурно-логические схемы, так как они более информационно емкие и универсальные; хотя на практике, используются более сотни методов визуального структурирования - от традиционных диаграмм и графов до «стратегических» карт (roadmaps), лучевых схем-пауков (spiders), казуальных цепей (casual chains) и интеллектуальных карт (mind maps), что обусловлено различиями в природе, особенностях и свойствах знаний различных предметных областей [7, с. 123]. Формирование визуального мышления способствует иллюстрации изменений процессов, твор- честву, развитию стереоскопичности, трехмерного восприятия, которые «многократно усиливается при использовании возможностей компьютера» [3]. В подобном процессе сам субъект есть предел для познания окружающего мира. Что станет критерием логики отбора информации? Каково будет методическое оснащение изучения визуального объекта? Частность позиций, отсутствие последовательности, очередности, важности, знаний, инструкции, методик работы с визуальными религиозными компонентами, бедность выбора, подмена понятий, не будет способствовать формированию системного мышления.

Дудник С.И., Марков Б.В., изучая трансформации образования в цифровую эпоху, делают следующие положения: 
1. если слово воздействует на мышление благодаря значению, то аудиовизуальные медиа возбуждают желания, формируют «клиповое сознание»;

2. новые медиа, с одной стороны, открывают возможности развития визуальных и эмоциональных способностей учащихся, а с другой - блокируют живое межличностное общение;

3. для развития рефлексивного опыта новые образовательные программы должны быть дополнены герменевтическими и семиотическими техниками обучения, способствующими пониманию смысла, обеспечивающими живое межличностное общение;

4. повышение производительности образования путем внедрения цифровых технологий сопровождается усилением электронного контроля и управления;

5. необходимо создание такой педагогической атмосферы, в которой культивируются свобода и ответственность, доверие и дружба [2, с. 214].

Поэтому, обнаружение подобных рисков, связанных с использованием наглядных форм в объяснении религии, указывает на сложность процесса восприятия религиозного явления и может привести к ошибкам восприятия, в крайнем случае, к социальным катаклизмам. Как делает вывод доктор педагогических наук Е.Ю. Ромашина, исследовав визуализацию религии в пособиях XIX века, сегодня религиозная тема все еще не имеет наработанного опыта выстраивания диалога с учеником [9, с. 81]. Существуют лишь частные методики религиоведческих школ и конфессиональных направлений. Поэтому, данный способ представления следует назвать в отношении изучения религии дополнительным, а не основным методом обучения. «Успехи визуализации, достигнутые в науке, позволяют говорить о том, что после грандиозного визуального поворота XX столетия, мы стоим на неком наблюдательном пункте и видим мир гораздо глубже, виртуальнее, чем мог себе представить самый смелый наблюдатель прошлого, однако утверждать аналогично, что с высоты цифровых достижений мы воочию смотрим на философию и пронизывающие ее процессы мышления, даже сквозь всю мощь визуального аппарата инфографики - слишком рано. Философия еще крепко держится невидимого мира идей, а существующие ныне визуализации постоянно демонстрируют нам как свою собственную познавательную непрочность, так и фундамента, на котором базируется все здание визуализации философского знания. Однако это не может являться веским аргументом в пользу отказа от визуализации, это значит, что она должна искать свою дорогу к философии, тем более что сделано в этом направлении уже очень многое» [4, с. 456]. Таким образом, визуально-семантическое кодирование и распознание цифровой визиософии необходимы для исследования в философии, а также для изучения развития религиозной мысли, религиозных традиций и др., в процессе изучения религий мира. Благодаря цифровым технологиям возможно расширить информационное поле гуманитарных исследований [6], в том числе в области религии.

\section{ЛИТЕРАТУРА}

1. Гильдебранд, Д. фон. Сущность христианства. Режим доступа: https://psychoanalysis.pro/lib/gildebrand-lib/gilderbrant_sustchnost_hristianstva/page02. htm. (Дата обращения: 17.08.2021).

2. Дудник С.И., Марков Б.В. Кризис образования в цифровую эпоху // Вестник С.-Петерб. ун-та. Философия и конфликтология. 2020. Т. 36, вып. 2. С. $214-226$. Режим доступа: https://doi.org/10.21638/spbu17.2020.201 (Дата обращения: 26.05.2021).

3. Крюкова, С.А. Понимание визуального мышления // Аналитика культурологии / Тамбовский гос. ун-т им. Г.Р. Державина. Тамбов, 2012. № 1(22). С. $152-155$.

4. Макулин, А.В. Визиософия: монография. Архангельск: Изд-во СГМУ, 2017. 480 с.

5. Макулин, А.В. Визуализация философии и цифровая визиософия // Вестник Сев. (Аркт.) федерал. ун-та. Серия: Гуманитарные и социальные науки. Архангельск, 2016. № 3. С. 62-72.

6. Можаева, Г.В. DIGITAL HUMANITIES: цифровой поворот в гуманитарных науках // Гуманитарная информатика. 2015. № 9. С. 8 - 23.

7. Полякова Е.В. Применение способов и методов визуального мышления в современном образовании // Известия ЮФу. Технические науки. 2012. № 10(135). C. 120-124.

8. Рахинский, Д.В. Социальное значение информатизации образования // Проблемы современной аграрной науки : материалы междунар. заоч. науч. конф. / Красноярский гос. аграр. ун-т. Красноярск, 2015. С. 203-205.

9. Ромашина, Е.Ю. Визуализация религии в российских азбуках и букварях XIX - начала XX в. // Вестник ПСТГУ. Серия IV: Педагогика. Психология. 2017. Вып. 46. C. 67-85.

10. Ромащенко, А.А., Ромащенко, М.А. Онтология визуального образа и цифровая реальность современной философской визуализации // Вестник Омского гос. пед. ун-та. Гуманитарные исследования. 2018. № 4(21). С. 39-42.

11. Тихомирова, И.В., Иванов, И.И., Омарова, П.Г. Реализация принципа визуализации в процессе обучения // Проблемы современного педагогического образования. 2018. № 60-1. С. 307-309. 